\section{ОХРАНА ОКРУЖАЮЩЕЙ СРЕДЫ И КРИМИНОЛОГИЯ (ПАМЯТИ ДОКТОРА ЮРИДИЧЕСКИХ НАУК, ПРОФЕССОРА ОЛЬГИ ЛЕОНИДОВНЫ ДУБОВИК)}

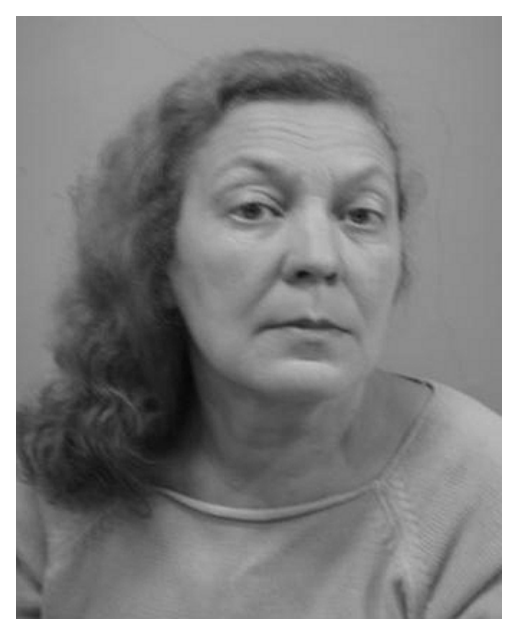

Боголюбов Сергей Александрович, доктор юридических наук, профессор, заслуженный деятель науки Российской Федерации. Должность: научный руководитель. Место работы: Институт законодательства и сравнительного правоведения при Правительстве Российской Федерации. Подразделение: отдел экологического u аграрного законодательства. E-mail: bogolyubovsa@mail.ru

Устюкова Валентина Владимировна, доктор юридических наук, профессор. Должность: заведующий, профессор. Место работы: Институт государства и права Российской Академии наук, РГАУ - МСХА имени К.А. Тимирязева. Подразделение: сектор экологического, земельного и аграрного права, кафедра правоведения. E-mail: ustyukova.v@yandex.ru

Мисник Галина Анатольевна, доктор юридических наук, профессор. Должность: профессор. Место работы: Российский государственный университет правосудия. Подразделение: кафедра земельного и экологического права. E-mail: galmisnik@yandex.ru

Редникова Татьяна Владимировна, кандидат юридических наук. Должность: старший научный сотрудник. Место работы: Институт государства и права Российской Академии наук. Подразделение: сектор экологического, земельного и аграрного права. E-mail: trednikova@yandex.ru

Куделькин Николай Сергеевич, кандидат юридических наук. Должность: ведущий научный сотрудник. Место работы: Институт государства и права Российской Академии наук. Подразделение: сектор экологического, земельного и аграрного права. E-mail: ecolaw@igpran.ru

Аннотация: наука экологического права понесла большую утрату - на 72 году жизни скончалась доктор юридических наук, профрессор Ольга Леонидовна Дубовик. Благодаря своему широкому научному кругозору она не замыкалась в рамках одной юридической специальности. Ее труды отличал междисциплинарный подход к рассмотрению проблем уголовного, международного, административного, других отраслей права. Она активно проводила сравнительно-правовые исследования российского законо- дательства и законодательства зарубежных стран, их наднациональных образований.

Всего О.Л. Дубовик опубликовала более 400 научных работ, в том числе фундаментальные труды «Причины экологических преступлений» (М., 1988; $в$ соавторстве с супругом А.Э. Жалинским), «Механизм действия права в охране окружающей среды» (М., 1994), «Экологические преступления. Комментарий к 26 главе Уголовного кодекса РФ» (М., 1998), «Экологическое право Восточной Европы» (М., 2018). Она являлась ответственным редактором практического пособия для экологической милиции (М., 2003), коллективной монографии «Юридическая ответственность за экологические правонарушения» (М., 2011).

Ольга Леонидовна организовала комментирование законодательных актов, входящих в систему экологического, земельного, иного природоресурсного законодательства. Ее комментарии к законам отличают системность, научная обоснованность структуры, практическая направленность содержания. О.Л. Дубовик исследовала направления взаимодействия и противоречий экологической и аграрной политики Европейского союза (ЕC), призванных обеспечить жизнедеятельность человека и человечества, выступала за развитие «эколого-дружественного» сельского хозяйства в России. О.Л. Дубовик уделяла время педагогической деятельности, руководству аспирантами и соискателями ученых степеней, преподаванию в высших юридических учебных заведенияx.

О.Л. Дубовик творчески проектировала модели механизма действия экологического права на основе маситабных социологических исследований: в ее трудах получило развитие новое научное направление - экологическая криминология. Она исследовала проблемы экологической коррупции, экологической сертифрикации, экологического лицензирования, незаконной торговли природными ресурсами, окружающей средой. Последней ее опубликованной монографрией стала «Экологическая конфликтология (предупреждение и разрешение эколого-правовых конфрликтов)» (М., 2019), являющаяся итогом ее многолетних исследований.

В круг научных интересов Ольги Леонидовны входили вопросы смежных с экологическим правом отраслей - земельного, иного природоресурсного, аграрного права. Она входила в состав авторского коллектива учебников «Земельное право» (М. 2013, 2014 и др.), была ответственным редактором Комментариев к Земельному кодексу Российской Федерации (М., 2013 и др.), к Водному кодексу Российской Федерации (2011), к Федеральным законам «О переводе земель или земельных участков из одной категории в другую» и «О землеустройстве (2012).

Ольга Леонидовна активно сотрудничала с российскими и зарубежными научными организациями, принимала участие в совместных проектах. В ИНИОН РАН она издала сборники научных трудов ученых разных стран - »Современное экологическое право в России и за рубежом» (М.,2001), «Современное медицинское право в России и за рубежом» (М.,2003). Она постоянно участвовала в научно-практических конфреренциях эколого-правовой и уголовно-правовой направленности, проводимых в России, Германии, Польше. Участвовала в международных проектах «Уголовно-правовая охрана окружающей среды» (2. Фрайбург, ФРГ, 1988-1989 ге.); «Рациональная эколо- 
гическая политика - рациональное экологическое право» (г. Билефельд, ФРГ, 1998-1999 ге.).

Владея немецким, польским языками, Ольга Леонидовна регулярно информировала российскую научную общественность о современных тенденциях развития экологического, уголовного права, криминологии за рубежом, а зарубежных читателей - о российском законодательстве, опыте, отечественных исследованиях. Она постоянно рецензировала труды ведущих ученых-юристов в сфрере экологического, уголовного права России, других европейских стран, анализировала экологическое право Европейского союза.

Смерть главного научного сотрудника Института государства и права Российской Академии наук, докмора юридических наук, профрессора О.Л. Дубовик заметная потеря научного эколого-правового российского и международного сообщества.

Ключевые слова: экологическое законодательство; охрана окружающей природной среды; юридическая ответственность за экологические правонарушения; внимание к обучению и воспитанию молодых ученых; международное экологическое сотрудничество.

\section{ENVIRONMENTAL PROTECTION AND CRIMINOLOGY (IN MEMORY OF PROFESSOR O.L. DUBOVIK)}

Bogolyubov Sergey Alexandrovich, Doctor of Law, Professor, Honored Scientist of the Russian Federation. Position: scientific director. Place of employment: Institute of Legislation and Comparative Law under the Government of the Russian Federation. Division: Department of Environmental and Agricultural. E-mail: bogolyubovsa@mail.ru

Ustyukova Valentina Vladimirovna, Doctor of Juridical Sciences, Professor. Position: Head, Professor. Place of employment: Institute of State and Law of the Russian Academy of Sciences, Russian State Agrarian University-Moscow State Agricultural Academy named after K. A. Timiryazev. Division: sector of environmental, land and agrarian law, department of Law. E-mail: ustyukova.v@yandex.ru

Misnik Galina Anatolyevna, Doctor of Juridical Sciences, Professor. Position: Professor. Place of employment: Russian State University of Justice. Division: Department of Land and Environmental Law. E-mail: galmisnik@yandex.ru

Rednikova Tatyana Vladimirovna, Candidate of Legal Sciences. Position: Research Associate. Place of employment: Institute of State and Law of the Russian Academy of Sciences. Division: sector of environmental, land and agricultural law. E-mail: trednikova@yandex.ru

Kudelkin Nikolay Sergeevich, Candidate of Legal Sciences. Position: Research Associate. Place of employment: Institute of State and Law of the Russian Academy of Sciences. Division: sector of environmental, land and agricultural law. Email: ecolaw@igpran.ru

Annotation: the science of environmental law has suffered a great loss - at the age of 72, Doctor of Law, Professor O.L. Dubovik died. Thanks to her broad scientific outlook, she was not confined to a single legal specialty. Her works were distinguished by an interdisciplinary approach to the consideration of problems of criminal, international, administrative, and other branches of law. She actively conducted comparative legal studies of Russian legislation and the legislation of foreign countries, their supranational entities.

In total, O. L. Dubovik published more than 400 scientific works, including the fundamental works "The causes of environmental crimes» (Moscow, 1988; co-authored with her husband A. E. Zhalinsky), "The mechanism of law in environmental protection» (Moscow, 1994), «Environmen- tal crimes. Commentary to Chapter 26 of the Criminal Code of the Russian Federation» (Moscow, 1998), "Environmental Law of Eastern Europe» (Moscow, 2018). She was the responsible editor of the practical manual for the environmental police (Moscow, 2003), the collective monograph "Legal responsibility for environmental offenses» (Moscow, 2011).

Olga Leonidovna organized comments on legislative acts included in the system of environmental, land, and other natural resource legislation. Her comments on the laws are distinguished by the systematic nature, scientific validity of the structure, and practical orientation of the content. O. L. Dubovik studied the areas of interaction and contradictions of the EU environmental and agricultural policy, designed to ensure the life of man and humanity, advocated the development of "eco-friendly» agriculture in Russia. O. L. Dubovik devoted time to teaching, directing graduate students and applicants for academic degrees, teaching in higher legal educational institutions.

O. L. Dubovik creatively designed models of the mechanism of action of environmental law on the basis of largescale sociological research: in her works, a new scientific direction was developed - environmental criminology. She has researched the problems of environmental corruption, environmental certification, environmental licensing, illegal trade in natural resources, the environment. Her last published monograph was «Ecological Conflictology (prevention and resolution of ecological and legal conflicts)" (Moscow, 2019), which is the result of her many years of research.

Olga Leonidovna»s research interests included issues related to environmental law - land, other natural resources, and agricultural law. She was a member of the author»s team of textbooks "Land Law» (M. 2013, 2014, etc.), was the responsible editor of Comments to the Land Code of the Russian Federation (M., 2013, etc.), to the Water Code of the Russian Federation (2011), to the Federal Laws "On the transfer of land or land plots from one category to another» and "On Land Management» (2012).

Olga Leonidovna actively collaborated with Russian and foreign scientific organizations, took part in joint projects. At INION RAS, she published collections of scientific works of scientists from different countries - "Modern environmental law in Russia and abroad" (Moscow, 2001), "Modern Medical law in Russia and Abroad» (Moscow, 2003). She constantly participated in scientific and practical conferences of environmental and criminal law orientation held in Russia, Germany, and Poland. Participated in international projects "Criminal law protection of the environment» (Freiburg, Germany, 1988-1989); "Rational environmental policy - rational environmental law» (Bielefeld, Germany, 1998-1999).

Speaking German and Polish, Olga Leonidovna regularly informed the Russian scientific community about current trends in the development of environmental, criminal law, and criminology abroad, and foreign readers about Russian legislation, experience, and domestic research. She constantly reviewed the works of leading legal scholars in the field of environmental and criminal law in Russia and other European countries, and analyzed the environmental law of the European Union.

The death of the chief researcher of the Institute of State and Law of the Russian Academy of Sciences, O.L. Dubovik - is a significant loss of the scientific ecological and legal Russian and international community.

Keywords: environmental legislation; environmental protection; legal responsibility for environmental of- 
fenses; attention to the training and education of young scientists; international environmental cooperation.

Наука экологического права понесла большую утрату - на 72 году жизни скоропостижно скончалась доктор юридических наук, профессор Ольга Леонидовна Дубовик - один из ведущих специалистов в данной отрасли права и законодательства. Она родилась в городе Уфе 22 ноября 1949 г. После окончания в 1972 г. с отличием юридического фракультета Львовского государственного университета с 1972 по 1975 г. обучалась в аспирантуре Всесоюзного института по изучению причин и разработке мер предупреждения преступности Прокуратуры Союза ССР. Под руководством академика В.Н. Кудрявцева подготовила и в 1976 г. защитила кандидатскую диссертацию на тему: «Принятие решения в механизме преступного поведения». Впоследствии активно участвовала в междисциплинарных научных исследованиях, активно применяла в своей деятельности методологию, идеи, концепции своего учителя. В разгар конституционного кризиса и под звуки движения по улице Знаменка города Москвы бронетехники - 4 октября 1993 г. защитила докторскую диссертацию по специальности 12.00.06 на тему: «Механизм действия экологического права (юридический и социологический аспекты)» (официальные оппоненты - С.А. Боголюбов, И.А. Иконицкая, Г.В. Чубуков; ведущая организация - кафедра правовой охраны окружающей среды юридического фракультета Санкт-Петербургского государственного университета)) в диссертационном совете (председатель Н.И. Краснов, ученый секретарь В.В. Устюкова) при ИГП $\mathrm{PAH}$, с которым была связана вся ее последующая научная жизнь: здесь она проработала сорок пять лет (с 1976 г.), в последнее время - в должности главного научного сотрудника сектора экологического, земельного и аграрного права.

В 1983 г. О.Л. Дубовик стала соавтором ставшей известной монографии на 225 страницах »Эффрективность юридической ответственности в охране окружающей среды». В главе «Борьба с экологическими правонарушениями средствами юридической ответственности» ею с опорой на криминологические знания написаны параграфы о понятии и классификации экологических правонарушений, об особенностях правоприменительной деятельности в охране окружающей среды, о понятии эффективности юридической ответственности за экологические правонарушения, о методике исследования проблемы. В главе «Международный опыт применения юридической ответственности в борьбе с экологическими правонарушениями» Ольга Леонидовна написала об ответственности за нарушение законодательства об охране окружающей среды в европейских социалистических странах».

В целиком написанной ею пятой главе «Эффрективность уголовной ответственности за преступные посягательства на окружающую среду» О.Л. Дубовик, анализируя состояние эффективности уголовной ответственности, писала о латентности (скрытости) экологических посягательств, оценке деятельности природоохранных и правоохранительных органов, результатах выборочных исследований, слабой применяемости уголовно-правовых норм к экологическим преступлениям, причинах этой низкой применяемости, заключающихся в пробелах и противоречиях законодательства, недостаточной квалификации правоприменителей, низкой квалификации судебно- следственных работников. Здесь же ею рассмотрены пределы действия уголовной ответственности и, самое главное, основные пути повышения эффективности уголовной ответственности, среди которых: приведение уголовного законодательства в соответствие с основополагающими принципами охраны окружающей среды; обеспечение служебной роли норм уголовного права по отношению к природоохранительному законодательству для выполнения его требований; устранение несогласованности в условиях криминализации и санкциях; устранение препятствий в установлении критериев разграничения административных правонарушений и преступлений; использование солидной базы научных исследований.

Автором предлагались научные, обоснованные богатыми социологическими исследованиями предложения о преодолении разбросанности уголовно-правовых норм экологической направленности по разным главам Уголовного кодекса (что было осуществлено при активном участии О.Л. Дубовик в УК РФ 1996 г), ликвидации неоправданных различий в УК союзных республик (что произошло после роспуска Союза ССР), нецелесообразности чрезмерного расширения уголовной репрессии в сфере охраны окружающей среды с учетом вспомогательной роли уголовного права (не преодолено до сих пор - у некоторой части элиты остается надежда на усиление карательных мер), установлении более четких критериев криминализации ответственности за посягательства на природу с учетом вредности совершенных деяний и опасности совершивших их лиц, форм их вины, об усилении взаимодействия природоохранных органов и правоохранительной системы, что предполагает постоянное внимание к решению этих проблем [20, с.115-140,174182].

Благодаря своему широкому научному кругозору Ольга Леонидовна не замыкалась в рамках одной юридической специальности. Ее труды отличал междисциплинарный подход, в сферу ее интересов помимо экологического и уголовного права входили проблемы международного, административного, других отраслей права. Активно проводила сравнительноправовые исследования российского законодательства и законодательства зарубежных стран, их наднациональных образований. Всего О.Л. Дубовик опубликовано более 400 научных работ, в том числе такие фундаментальные труды как «Экологические преступления. Комментарий к главе 26 УК РФ» (М.,1998), «Экологическое право Восточной Европы» (М.,2018). Являлась ответственным редактором книги «Практическое пособие для экологической милиции» (М.,2003), монографии «Юридическая ответственность за экологические правонарушения» (М.,2011), многочисленные комментарии к экологическому законодательству, вышедшие в 2011-2016 гг. [5; 13].

Уже во втором десятилетии XXI века опубликовано несколько изданий Комментария к Федеральному закону «Об охране окружающей среды» под редакцией О.Л. Дубовик объемом около 60 печатных листов в электронном и бумажном видах, где ею были собраны ученые ИГиП РАН, преподаватели государственных Московского университета технологий и управления, Удмуртского университета, Белгородского университета кооперации, экономики и права, Российской академии правосудия Верховного Суда Российской Федерации (ныне - университет), Правовой академии Минюста РФ, Российской академии народного хозяйства и государственной службы при Президенте РФ, а также 
практики: нотариус, депутат, юрист фрирмы, всего шестнадцать авторов. Отличительными чертами этого Комментария, что признается многочисленными читателями, служат его проецирование не только на студентов юридических и иных вузов, но и на практических работников, осуществляющих управление, контроль, надзор за соблюдением законности и экологического правопорядка, реализующих природоохранные мероприятия - путем комплексного авторского толкования положений закона в связи с нормами конституционного, административного, гражданского, налогового и иного смежного, то есть экологизированного законодательства, ознакомления с наиболее типичными решениями судов и административных органов.

Традиционными в этом Комментарии стали вводные замечания к каждой главе (порой дискуссионные) как с позиций теории, так и с точки зрения правоприменения, перечисления и разъяснения основных, необходимых для понимания сути предписаний понятий, специальных терминов, конструкций, оборотов, освещение выделенных на основании эмпирических исследований наиболее часто встречающихся проблемных ситуаций с рекомендациями по преодолению связанных с ними трудностей. При характеристике статей показывались их цели, сферы действия, адресаты правил, запретов, ограничений со ссылками на источники юридического, биологического, иного естественно-научного характера, обусловленного спецификой регулируемого предмета, объекта общественных отношений, обращалось внимание на необходимость и способы преодоления правоприменителями противоречивости, пробельности, декларативности, дублирования отдельных норм, иных «черных дыр» экологического законодательства, чтобы способствовать грамотной, профессиональной их реализации. Авторы Комментария не избегали оценок и своих разъяснений перманентно вносимых в Закон дополнений, обусловленных не столько развитием экологических правоотношений, сколько муниципальной, административной, управленческой, федеративной реформами, социально-экономическими подвижками, вызывавшими изменения экологического контроля, надзора, мониторинга, введение технических регламентов, повышение требовательности к нефтеперерабатывающему, мелиоративному комплексам, ввозу ядерных материалов, радиоактивных отходов для хранения.

Комментируя преамбулу Закона об охране окружающей среды, О.Л. Дубовик не ограничивалась анализом ее достаточно абстрактного содержания, но творчески размышляла о не столь очевидных провозглашаемых ею целях, как, например, гарантировании конституционных экологических прав граждан, реализации основ государственной экологической политики (к которым автор комментария причисляла не только концепции, стратегии, доктрины и иные масштабные документы, но и весь комплекс законодательных, иных нормативных правовых актов). Актуальным представляется и в настоящее время поиск взаимосвязей с иными видами политики - энергетической, транспортной, градостроительной, сельскохозяйственной, промышленной и др., которые важны, поскольку должны соответствовать экологическим требованиям национального и международного масштаба. Эти инновационные идеи были продолжены и развиты коллегами в последующих монографиях $[1 ; 2 ; 19]$. Здесь устанавливаются временнь́е, пространственные пределы действия Закона, а также предпринимается очередная (не без дискуссий) попытка вычленения из общих отношений «общество-природа» предмета правового регулирования через ограничения хозяйственной, иной деятельности, изменяющей состояние, качество окружающей среды как в негативную, так и в позитивную стороны. Не меньший интерес вызывали предложенные Ольгой Леонидовной характеристики свойств понятий, обозначающих их терминов, видение структуры, иерархии, круга источников законодательства об охране окружающей среды и ее компонентов, значение его принципов, связей с принципами устойчивого развития, принципами смежных отраслей и международного экологического права; наибольшая трудность виделась в излишней абстрактности Закона об охране окружающей среды, потребностях сопоставлять его положения с конкретными предписаниями других законов, подзаконных актов, поиском более определенных, предоставляющих права и устанавливающих обязанности норм. Были отмечены другие дефекты Закона, препятствующие эффективному применению, охарактеризованы недостатки экономического механизма охраны окружающей среды, системы экологических требований к осуществлению хозяйственной деятельности, что имело важное теоретическое и практическое значение (многие недостатки, отмеченные в данном комментарии, были устранены в дальнейшем при разработке законов о внесении изменений в Федеральный закон «Об охране окружающей среды»).

Ольга Леонидовна была организатором и вдохновителем работы над комментариями к ряду других законодательных актов, входящих в систему экологического, земельного, иного природоресурсного законодательства. Заслуга ее состоит в том, что она умела сплачивать вокруг себя широкий круг авторов, последовательно выстраивать работу над комментариями, максимально использовала накопленный авторами потенциал в исследовании комментируемых законов. Комментарии, написанные под ее руководством, отличают системность, научная обоснованность структуры изложенного в них материала, практическая направленность содержания. Перед авторами ставилась задача изучать проблематику, связанную с применением комментируемых статей и авторы, которые в большинстве являлись учениками Ольги Леонидовны, справлялись с этой задачей, с высокой ответственностью относясь к порученному делу. При планировании работы над комментариями к законодательным актам определялись ее направления с учетом актуальных проблем; реализация в последующем законотворческом процессе предложений, которые высказывались в комментариях, свидетельствует о научной интуиции, прозорливости руководителя авторского коллектива[15].

При написании комментариев к статье освещались сфера действия нормы, используемый понятийный аппарат, юридические и фрактические последствия реализации требований. Применялся новый подход к анализу правового регулирования, состоящий в оценке действия норм с позиций цели законодательного акта; это использовалось и при исследовании эффективности юридической ответственности за экологические правонарушения, чему было посвящено большинство трудов О.Л. Дубовик.

Результатом многолетних исследований в данной области явилась коллективная монография «Юридическая ответственность за экологические правонарушения» [21], в главе 1, параграфрах 2 и 3 главы 2 кото- 
рой Ольга Леонидовна в системном изложении показала факторы, влияющие на эффективность юридической ответственности в данной области, к числу которых были отнесены: стабильность экономики, приоритеты социально-экономического развития, разработанность научных основ экологической политики в современных условиях глобализирующегося мира, потребности получения достоверных научных данных об экологической преступности и иных правонарушениях, выделены наиболее актуальные направления исследований в данной области, а именно, квалификация вины в экологических преступлениях, теоретические основы построения составов экологических правонарушений, соотношение общих и специальных составов экологических преступлений, потребность введения новых составов экологических правонарушений.

О.Л. Дубовик осуществляла проектирование модели механизма действия экологического права на основе масштабных социологических исследований: в ее трудах получило развитие новое научное направление экологическая криминология по результатам исследования экологической коррупции в таких сферах, как незаконная торговля природными ресурсами, окружающей средой, экологическая сертификация и экологическое лицензирование, теория причин экологических преступлений, теория экологических конфликтов. Последней ее опубликованной монографией стала «Экологическая конфликтология (предупреждение и разрешение эколого-правовых конфликтов)» (М., 2019) [11], в значительной степени являющаяся итогом ее многолетних исследований данной проблематики. Научное наследие О.Л. Дубовик, в котором преобладают научные работы фундаментального характера, значимые для правовой доктрины и правовой политики, долгие годы будет служить основой для новых научных исследований в сфере экологического, уголовного права [6; 8, с. 23-28; 11].

В круг научных интересов Ольги Леонидовны входили вопросы смежных с природоохранным правом отраслей - земельного, иного природоресурсного, аграрного права. Она входила в состав авторского коллектива учебников «Земельное право» под ред. Н.Г. Жаворонковой и И.О. Красновой (М.: Юрайт, 2013. 580 с. и все последующие переиздания) и под ред. Г.А. Мисник (М.: Норма, 2014. 320с.). О.Л. Дубовик была ответственным редактором и соавтором учебнопрактического комментария к земельному законодательству Российской Федерации (М.: Эксмо, 2006. 1149 с.) и Комментария к Водному кодексу РФ (2011 г. - для системы «Гарант» и «КонсультантПлюс»), к Федеральным законам «О переводе земель или земельных участков из одной категории в другую» и «О землеустройстве» (для «КонсультантПлюс», 2012) и др.

О.Л. Дубовик исследовала также основные направления взаимодействия и противоречий экологической и аграрной политики ЕC, призванных обеспечить жизнедеятельность человека и человечества наряду с решением подчиненных этой цели задач: сохранение биоразнообразия, ликвидация голода, недопущение утраты площадей сельскохозяйственных угодий, снижение рисков в результате применения опасных пестицидов и агрохимикатов, уменьшение негативного воздействия на процессы глобального потепления вследствие поступления метана, обеспечение рабочих мест, увеличение доли биопродуктов; она выступала за развитие «эколого-дружественного» сельского хо- зяйства в России. Заслуживает уважения активная гражданская позиция О.Л. Дубовик в поддержку сохранения аграрного права в номенклатуре научных специальностей ВАК, довольно резко она называла предложения о его исключении из перечня абсурдом и безумной идеей, которую трудно понять, «учитывая, что сельскохозяйственное производство так же, как и энергетика, транспорт, здравоохранение, образование, относится к абсолютно необходимым условием обеспечения жизни человека и существования человечества, конечно, если они не будут подрывать базиса их жизнедеятельности - окружающей среды» [10, с. 3543; 14, с. 27-35; 16, с. 2057-2060; 17].

О.Л. Дубовик в своей работе много внимания уделяла сотрудничеству с другими российскими и зарубежными научными организациями, неоднократно принимала участие в совместных проектах. В ИНИОН РАН ею были изданы сборники научных трудов ученых из разных стран - „Современное экологическое право в России и за рубежом» (М., 2001), «Современное медицинское право в России и за рубежом» (М., 2003). Была постоянным участником научно-практических конференций ИГП РАН, Института законодательства и сравнительного правоведения при Правительстве Российской Федерации, МГЮА им. О.Е. Кутафина, встреч ученых, преподавателей экологического, земельного права и школ молодых юристов-экологов, проводимых деканом юридического факультета МГУ им. М.В. Ломоносова проф. А.К. Голиченковым. Еще в декабре 2019 года в Московском институте геодезии и картографии еe большой содержательный доклад сравнительного характера о современных экологоправовых достижениях и просчетах вызвал большой научный и практический интерес. Она выступала также на международных научных мероприятиях экологоправовой и уголовно-правовой направленности, проводимых в разных странах (Германии, Китае, Польше), где выбирала для своих докладов наиболее актуальные и общественно значимые темы. Была признана в Обществе Макса Планка (1988-1998 гг.), фондах Александра фон Гумбольдта (1990-1991, 1993-1994 гг.) и Дж. и К. Мак-Артур (1996-1997 гг.), Вашингтонском университете (2000-2002 гг.). Участвовала в международных проектах «Уголовно-правовая охрана окружающей среды» (г. Фрайбург, ФРГ, 1988-1989 гг.); «Рациональная экологическая политика рациональное экологическое право» (г. Билефельд, ФРГ, 1998-1999 гг.).

Еще одна грань ее таланта - это активное, обстоятельное рецензирование монографий, учебных пособий как российских, так и иностранных авторов по экологическому, уголовному праву, криминологии, земельному, горному праву, иным природоресурсным отраслям. Ольга Леонидовна владела немецким и польским языками: одну из своих научных задач она видела в информировании российской научной общественности о современных направлениях, тенденциях развития экологического, уголовного права, криминологии за рубежом, а зарубежных читателей - о российском законодательстве, опыте, отечественных исследованиях. В периодических научных изданиях можно найти подготовленные ею многочисленные рецензии на труды ведущих ученых-юристов в сфере экологического, уголовного права из России, Германии, Польши, других европейских стран. Пристальное внимание она уделяла анализу норм экологического права Европейского Союза, опубликовав по этой тематике более двадцати работ [9, с. 80-82]. 
О.Л. Дубовик большое внимание уделяла преподаванию учебной дисциплины экологического права в российских юридических вузах - Академическом правовом университете при ИГП РАН, МГЮА им. О.Е. Кутафина. Написанные ею на основе педагогического опыта учебники и учебные пособия, отличают глубина рассмотрения вопроса, стремление привить студентам в процессе изучения предмета умение анализировать, выходить со своими размышлениями за рамки учебника. Сотрудничала с ведущими юристами-экологами Германии Людвигом Кремером и Гертрудой ЛюббеВольфф, российскими издательствами: в издательстве «Проспект» ею было опубликовано учебное пособие «Экологическое право в вопросах и ответах» (2001, 2005, 2007) и учебник «Экологическое право» (2003); в издательстве «Юрист» книга «Экологическое право. Элементарный курс» (2002, 2004); в издательстве «Эксмо» был опубликован учебник «Экологическое право» $(2005,2008)$. В 2007 году под ее редакцией издательство «Городец» выпустило в свет учебник Людвига Кремера и Герда Винтера «Экологическое право ЕС» [7].

Ольга Леонидовна вела активную просветительскую работу по продвижению конструктивных экологоправовых идей и взглядов, сотрудничала с государственными органами в процессе обсуждения и принятия ими эколого-значимых решений. Являлась членом Научно-консультативного совета при мэре г. Москвы, Коллегии Департамента по природопользованию и охране окружающей среды Правительства г. Москвы, в 1994-1999 гг. была членом Высшего экологического совета при Государственной Думе Федерального Собрания Российской Федерации; существенна и юридической общественности известна ее роль в формировании главы 26 «Экологические преступления» Уголовного кодекса РФ 1996 года [3, с. 53-66; 4].

Значительную часть времени Ольга Леонидовна отдавала делу подготовки молодого поколения юристовэкологов: под ее непосредственным руководством в ИГП РАН защищено двадцать семь кандидатских и одна докторская диссертации. Начинающие преподаватели, молодые ученые знакомились с О. Л. Дубовик по ее трудам, нередко - по выступлениям на заседаниях школ молодых экологов-юристов, конференциях преподавателей экологического и земельного права, проводимых заведующим кафедрой экологического и земельного права, деканом юридического факультета МГУ им. М.В. Ломоносова профессором А.К. Голиченковым, других научно-практических конференциях; участников задевали ее доклады, посвященные сравнительному анализу российского и зарубежного законодательства, глубина суждений о перспективах развития экологического законодательства, современных вызовах, нуждающихся в исследовании юристамиучеными-экологами. Так Ольга Леонидовна согласилась ознакомиться с материалами изысканий Г.А. Мисник, осуществляемыми более двадцати лет, которые послужили основой для подготовки диссертации на соискание ученой степени доктора юридических наук, увенчавшейся в дальнейшем благодаря научному консультированию, наставничеству успешной защитой [18]. Свобода мышления была не только достоинством Ольги Леонидовны как ученого, но и нравственным камертоном в общении с учениками, что неизбежно было связано с риском разочарований, ошибок, но данную опасность удавалось преодолевать в условиях доброжелательности и требовательности. Научный руководитель, консультант радушно встреча- ла своих учеников, старалась словом и делом оказать им поддержку [12, с. 172-174]. Она была не только прекрасным ученым, любящей женой, матерью, бабушкой, но и верным товарищем, в жизни которых проявляла искренне участие; круг друзей бывал рядом во время ее пребывания в Москве, приездов из Германии от дочери Аллы Рерихт. Яркое впечатление оставляли встречи, общение с ней, когда за чашкой чая обсуждались наболевшие темы не только из профессиональной области, но из обыденной жизни людей. Главным признаваемым человеческим качеством Ольги Леонидовны была ее любовь к семье: настойчиво обучала внуков, проживающих в Германии, русскому языку, русской литературе, любви к А.С. Пушкину, к своей стране, стремилась к тому, чтобы русская культура присутствовала в жизни ее семьи, несмотря на удаленность от Родины.

Рассматривая компоненты охраны окружающей среды, О.Л. Дубовик обобщала практику их рационального использования, преобразовывала эмпирические исследования в теоретические выводы. Участвуя в подготовке комментария к Федеральному закону «Об охране атмосфрерного воздуха», отмечала существование актуальных проблем правового регулирования, которые связаны с установлением размеров вреда, доказыванием причинной связи между деянием и его последствиями (в материальных составах и составах поставления в опасность), определением форм вины. Обосновывая ответственное отношение к обращению с животным миром, его объектами, Ольга Леонидовна проявляла трогательную заботу о конкретных особях: однажды переживания из-за пропавшего кота, жившего у нее дома в Германии, тронули соседей и весь поселок участвовал в его поисках - любовь к животным были зовом души.

Осуществила Ольга Леонидовна посмертное четырехтомное издание работ А.Э. Жалинского, которое со свойственными ей настойчивостью, последовательностью формировала в соответствии с научными предпочтениями Альфреда Эрнестовича, определявшими направления его творчества в различные периоды жизни; присущее ей умение исследователя позволяло высветить грани научных достижений, гражданской позиции супруга; организовала и провела в Высшей Школе экономики (месте его последней работы) серьезную конференцию, посвященную трудам, деятельности, памяти.

Ольга Леонидовна Дубовик была талантливым ученым, хорошим товарищем, отзывчивым человеком, ее человеческие качества привлекали к ней людей. Ее уход из жизни является тяжелой потерей для российского и зарубежного эколого-правового сообщества. Светлая память об экологе-криминологе останется в сердцах людей, которые имели возможность знакомиться с ее трудами, с ней общаться.

\section{Список литературы}

1. Анисимов А.П., Попова О.В., Устюкова В.В. Обеспечение устойчивого развития сельских территорий: проблемы и перспективы // Современные проблемы теории экологического права: монография под общ. ред. А.П. Анисимова. М.: Юрлитинформ, 2019. 511 с.

2. Развитие экологического права на евразийском пространстве: монография / С.А. Боголюбов. М.: ИЗиСП, ИНФРА-М, 2020. 432 с.

3. Бринчук М.М., Боголюбов С.А., Дубовик О.Л., О.А. Супатаева. Проблемы развития системы российского 
экологического законодательства // Государство и право. 1995. № 2.

4. Бринчук М.М., Дубовик О.Л., Жаворонкова Н.Г., Колбасов О.С. Экологическое право: от идей к практике. М. ИГП РАН. 1997. 29 с.

5. Дубовик О.Л. Механизм действия права в охране окружающей среды. Монография. М.: Наука, 1984. 168 c.

6. Дубовик О.Л. Коммент. к гл. 26 Уголовного кодекса РФ / О. Л. Дубовик. М.: Спарк, 1998. 351с.

7. Дубовик О.Л. Дискуссионные вопросы перестройки курса экологического права // Экологическое право. Сб. материалов научно-практических конференций. Вып четвертый. Сост. А.К. Голиченков, И.А. Игнатьева, А.О. Миняев. М.: Юридический институт МИИТа. 2003. $443 \mathrm{c}$.

8. Дубовик О.Л. Уголовно-правовая охрана окружающей среды: история развития, задачи и перспектива (влияние идей В.В. Петрова на формирование и реализацию) // Экологическое право. 2009. № 2-3.

9. Дубовик О.Л. Значение исследований современной экологической политики: теория и практика. Рецензия на монографию С.А. Боголюбова «Реализация экологической политики посредством права» // «Черные дыры» в Российском законодательстве». 2019. № 2. С. $80-82$.

10. Дубовик О.Л. Современная аграрная политика EC: цели оптимизации, конфрликты, необходимость поиска экологических, социальных и экономических интересов // Экологическое право. 2019. № 3. С. 35-43.

11. Дубовик О.Л. Экологическая конфрликтология (предупреждение и

разрешение эколого-правовых конфрликтов): монография. М.: Норма, 2019. 280 с.

12. Дубовик О.Л., Гиряева В.Н. Экологические платежи: налоги или сборы? // Журнал российского права. 2000. № 9. С. 172-174.

13. Дубовик О.Л., Жалинский А.Э. Причины экологических преступлений. М.: Наука, 1988. 238 с.

14. Дубовик О.Л. Иванова А.Л., Калиниченко В.Т., Редникова Т.В., Рерихт А.А. Общие вопросы европейского экологического права: принципы и закономерности его развития и формирования // Экологическое право. 2007.

15. Дубовик О.Л., Кузнецова О.Н. Комментарий к Закону города Москвы «О государственном экологическом контроле в городе Москве». М.: Норма, 2007. 302 c.

16. Дубовик О.Л., Редникова Т.В. Актуальные проблемы правового регулирования оборота генетически модифицированных сельскохозяйственных культур в европейском праве. Анализ рисков и оценка влияния на окружающую среду // Право и политика. 2010. № 11. C. 2057-2060.

17. Козырь М.И. Аграрное право России: состояние, проблемы и тенденции развития. М.: Норма. 2008. 336 c.

18. Мисник Г.А. Возмещение экологического вреда в российском праве: дис. ... доктора юридических наук. М., 2008. 430 C.

19. Публичные и частные интересы в земельном и аграрном праве: теория и практика»: монография / Г.Л. Землякова, Н.Н. Мельников, О.А. Самончик, В.В. Устюкова / Отв. ред. В.В. Устюкова. М.: Институт государства и права РАН, 2019. 302 с.

20. Эффрективность юридической ответственности в охране окружающей среды: сб. ст. / АН СССР, Ин-т государства и права; отв. ред. О. С. Колбасов, Н. И. Краснов. М.: Наука, 1985. 226 с.

21. Юридическая ответственность за экологические правонарушения: монография / отв. ред. О. Л. Дубовик; Российская акад. наук, Ин-т государства и права. Москва: Ин-т государства и права Российской акад. наук, 2012. $170 \mathrm{c}$. 